\title{
Regional and local determinants of macrophyte community compositions in high- latitude lakes of Finland
}

2 Janne Alahuhta $^{1 *}$, Seppo Hellsten $^{2}$, Minna Kuoppala ${ }^{2}$ and Juha Riihimäki ${ }^{2}$

3

4

5

6

$7{ }^{1}$ University of Oulu, Department of Geography, FI-90014 University of Oulu, Finland,

$8 \quad{ }^{2}$ Finnish Environment Institute, Freshwater Centre, FI-90014 Oulu, Finland

9

10 *Correspondence: Janne Alahuhta. University of Oulu, Department of Geography, FI-90014

11 University of Oulu, Finland. Email: janne.alahuhta@ oulu.fi, GSM: +358 294488061.

12

13

14

15 KeYwORDS: Ancylus Lake, Aquatic plants, Finland, Glaciation, Grime's plant strategy,

16 Macrophytes, Species traits, Supra-aquatic lakes 
21 Species distributions are structured by regional and local determinants, which operate at multiple 22 spatial and temporal scales. The purpose of our work was to distinguish the relative roles of local 23 variables, climate, geographical location and post glaciation condition (i.e. delineation between 24 supra- and subaquatic lakes during the post-glacial Anculys Lake) in explaining variation in 25 macrophyte community composition of all taxa, helophytes and hydrophytes. In addition, we 26 investigated how these four explanatory variable groups affected macrophyte strategy groups based 27 on Grime's classification. Using partial linear regression and variation partitioning, we found that 28 macrophyte communities are primarily filtered by local determinants together with regional 29 characteristics at the studied spatial scale. We further evidenced that post glaciation condition 30 indirectly influenced on local water quality variables, which in turn directly contributed to the 31 macrophyte communities. We thus suggest that regional determinants interact with local-scale 32 abiotic factors in explaining macrophyte community patterns and examining only regional or local 33 factors is not sufficient for understanding how aquatic macrophyte communities are structured 34 locally and regionally. 
43 Species distributions are explained by regional and local determinants, operating at multiple spatial and temporal scales. Regional factors are related to broad-scale historical and biogeographical effects, originating, for example, from previous glaciations, current climate patterns, major dispersal barriers and evolutionary changes (Whittaker et al., 2001; Ricklefs, 2004). These regional determinants of species distributions are influential at continental (e.g., glaciations) and interregional (e.g., climate) scales over long temporal periods (Willis \& Whittaker, 2002). Local abiotic and biotic ecological factors structure local species distributions within short contemporary time periods, ranging from disturbances and environmental conditions to species interactions (Willis \&

51 Whittaker, 2002; Ricklefs, 2004). These regional and local determinants are hierarchically structured so that regional processes and constrains interact with local-scale biotic and abiotic factors in explaining species community patterns (Whittaker et al., 2001; McGill, 2010). Thus, studying only regional or local determinants may not be sufficient for understanding how species communities are structured locally and regionally (Ricklefs, 2004, Svenning et al., 2010).

Many studies have investigated the roles of regional vs. local factors and their impact on species distributions; however, disagreement exists concerning their relative importance in structuring local communities (Ricklefs, 2004; Soininen, 2014). Disparity over the dominance of regional and local factors in explaining local communities also stems from the differences between study systems in

61 relation to geographic location and habitat. For example, high-latitude regions can exhibit strong regional effects on local communities due to geographic variability in the influence of the past 63 glaciations (Svenning \& Skov, 2003; Svenning et al., 2010; Alahuhta et al., 2013). In freshwater ecosystems, variable patterns in the relative importance of regional and local determinants on local 
communities have strongly depended on the studied biological assemblage (De Bie et al., 2012; Alahuhta \& Heino, 2013; Viana et al., 2014; Heino et al., 2015; McCann, 2015). These freshwater examinations have focussed on distinguishing local environmental conditions from regional spatial processes in explaining local communities. However, much less attention is given to actual historical effects, such as the Pleistocene glaciation period, in explaining freshwater communities.

The latest major glaciation period in Europe took place during the Pleistocene, causing massive regional losses of fauna and flora (Svenning, 2003; Koch \& Barnosky, 2006). A several-kilometrethick ice sheet covered most of northern Europe (incl. the whole landmass of present-day Finland) until deglaciation began over 13000 BP (Eronen, 2005), creating a major barrier for species dispersal and leading to isolated populations (Svenning \& Skov, 2003). When the ice sheet slowly melted in present-day Northern Europe, a large post-glacial water body, called Ancylus Lake, emerged (9 $500-8300$ BP, Tikkanen \& Oksanen, 2002). Species dispersal possibilities were equally poor during the glaciation period, but melting of ice during the Ancylus Lake phase resulted in the rise of water level over 200 metres above the current sea level and enabled free dispersion of aquatic species (i.e., subaquatic area). However, high-altitude areas were above the maximum water level of Ancylus Lake and thus not enclosed by the lake (i.e., supra-aquatic area, Tikkanen \& Oksanen, 2002). As a result, dispersion potential of aquatic species was likely different between subaquatic and supra-aquatic areas, as supra-aquatic lakes were spatially and more effectively isolated from each other by surrounding land and were limited by dispersal process. No previous studies have yet examined whether freshwater communities established in subaquatic and supraaquatic lakes show different patterns of regional and local factors. 
Aquatic macrophyte communities are ecologically and scenically important components of highlatitude freshwater lakes by providing nutrition, shelter and breeding areas for other aquatic and terrestrial species (Toivonen \& Huttunen, 1995; Vestergaard \& Sand-Jensen, 2000; Alahuhta et al., 2016). Aquatic flora also store nutrients, decreases erosion and affect the quality and quantity of sediments (Lacoul \& Freedman, 2006; Alahuhta et al., 2012). Macrophytes can be classified into functional groups, of which helophytes (i.e., emergent species) and hydrophytes (i.e., aquatic plants growing on or below the water surface) form the most-recognized life forms (Toivonen \& Huttunen, 1995; Alahuhta et al., 2014). Helophyte and hydrophyte species respond differently to environmental conditions. Helophytes obtain carbon dioxide from the atmosphere, uptake nutrients from sediments and are more sensitive to cold winters, whereas hydrophytes mainly acquire carbon oxide and nutrients directly from water and are sheltered beneath the ice cover during winters (Toivonen \& Huttunen, 1995; Hellsten, 2001; Lind et al., 2014). Dispersal modes also vary to some extent between these functional macrophyte groups, as helophytes combine intensive vegetative growth with wind dispersed seed production resulting in high colonization capability (BarratSegretain, 1996; Saarnel et al., 2014). Oppositely, hydrophytes are more dependent on water and waterfowl for dispersing propagules to new habitats (Claussen et al., 2002; Soons et al., 2015). Although much is known about the relationships between aquatic flora and environmental conditions, fewer studies have examined the relative importance of local and regional factors in structuring local assemblages of different macrophyte functional groups.

Besides belonging to different functional plant groups, aquatic macrophytes can also be categorised based on life history strategy (Grime, 1977), in which species are classified as competitive (C), stress-tolerant (S) and ruderal (R). Competitors (C) are plant species growing in areas of low stress and disturbance, thus having good competition capabilities. Stress can be defined as conditions such as lack of light or nutrients, whereas disturbance can be caused by wind or drought. Competitors 
113 can outcompete other plants by reserving available resources such as growth area or nutrients.

114 Favourable characteristics of competitors include rapid growth rate, high productivity and wide 115 phenotypic plasticity. The latter property describes highly flexible morphology and reallocation of 116 resources depending on conditions experience by the plant. For example, the large-sized helophyte, 117 Phragmites australis, is a typical C-strategist representing aquatic plants. Stress-tolerant plant 118 species (S) occupy areas of high intensity stress and low intensity disturbance, such as in deep119 water environments. Species have adapted to this strategy with slow growth rates, long-lived leaves, 120 high rates of nutrient retention, and low phenotypic plasticity. They are adapted to environmental 121 stresses through physiological variability. Typical examples include large isoetids such as Isoetes 122 lacustris or Lobelia dortmanna with evergreen leaves adapted to lack of nutrients and light. Ruderal 123 plant species (R) are adapted to high-intensity disturbance and low-intensity stress. These species 124 are fast-growing, have short life cycles and vigorous seeds production. Plants that have adapted this strategy are often found colonizing recently disturbed land, and are often annuals. Typical examples are small-sized isoetids like Ranunculus reptans and Elatine hydropiper occupying the eroded littoral zone.

129 The overall purpose of our study was to investigate the importance of regional and local factors on 130 aquatic macrophyte communities in 80 Finnish lakes. Firstly (I), we researched the relative roles of 131 post glaciation condition, geographical location, climate characteristics and local water quality in 132 explaining variation in aquatic macrophyte composition of all taxa, helophytes and hydrophytes. 133 Secondly (II), we investigated if aquatic macrophytes categorized as dominant competitive, stress134 tolerant and ruderal plant groups, based on the life history strategy classification (Grime, 1977), 135 respond similarly to these four explanatory variable sets. Based on previous findings (Toivonen \& 136 Huttunen, 1995; Vestergaard \& Sand-Jensen, 2000; Alahuhta et al., 2014), we expected to find that 137 all macrophyte communities respond primarily to local determinants. We also hypothesised that 
138

139

macrophyte communities are affected by regional variables, as latitudinal gradient derived from climatic variation is known to structure macrophytes at regional scales (Heino \& Toivonen, 2008; Alahuhta, 2015). In addition, we supposed that glaciation period does not influence macrophyte communities anymore, because many plant species disperse efficiently, have wide range sizes and spatial processes have rarely been important factors controlling macrophytes even at regional scales (Barrat-Segretain, 1996; Claussen et al., 2002; Viana et al., 2014; Alahuhta et al., 2015).

\section{MATERIAL AND METHODS}

\section{Study area and supra delineation}

We used aquatic macrophyte data from 80 boreal lakes $\left(<100 \mathrm{~km}^{2}\right)$ distributed across Finland (Fig. 1). Half of the lakes (40) were situated in high-altitude supra-aquatic areas, which were above the maximum water level during the existence of Ancylus Lake in ca. 9000 BP (Table 1). The Ancylus Lake was the largest post-glacial sea lake in Fennoscandia, covering over $60 \%$ of Finland's surface area (Tikkanen \& Oksanen, 2002). As the supra-aquatic areas were not enclosed by the Ancylus Lake and terrestrial land surrounded supra-aquatic lakes in a way similar to modern times, aquatic plants established in these 40 lakes have been efficiently spatially isolated from each other by a non-habitable terrestrial matrix and thus limited by dispersal processes. Another 40 lakes were situated in subaquatic areas, which were below sea level during the existence of Ancylus Lake. A sudden rise in water level, when the Ancylus Lake was established, has likely led to the loss of many macrophyte species from their original sites. However, new colonies have probably formed in shallower areas, as species were able to disperse freely throughout the lake. These subaquatic lakes were randomly chosen from a larger set of lakes (see Alahuhta et al., 2012). The separation between supra- and subaquatic areas (Fig. 1) was based on the map found in Tikkanen \& Oksanen (2002). 
164 Aquatic macrophytes were surveyed using a main belt transect method, in which a five-metre-wide 165 transect was sampled from the upper eulittoral to the outer limit of vegetation, or to the deepest 166 point of the basin if vegetation covered the entire lake (see method in Kanninen et al., 2013a). 167 Macrophytes were observed by fording or by boat, with the assistance of rakes and hydroscopes. 168 The number of transects varied between six and 36 (mean $=13, \mathrm{SD}=5.5)$, depending on lake size. 169 These surveys were carried out during the growing season between 2006 and 2011. During the 170 surveys, species consisted of all aquatic vascular plants and macroalgae from the family Characeae 171 were recorded and these documented species were studied in this work (Alahuhta et al., 2012). The 172 total number of recorded species was 108 of which 46 were helophytes and 62 were hydrophytes.

174 Macrophyte community composition variables were calculated separately for all taxa, helophytes 175 and hydrophytes. In addition, we separated plant species into dominant plant strategy groups (C, S 176 or R) based on Grime (1977) and Grime et al. (1988). Information on 36 species traits was based on 177 Jalas (1958, 1965, 1980). Aquatic plant strategy properties based on Rørslett (1989) and Murphy et 178 al. (1990) were used to define the dominant strategies for all the studied plants. The list of dominant 179 plant strategy groups for each species is given in Online Resource S1. If species possessed a certain 180 species trait, this was recorded and the cumulative number of species traits over all 36 traits 181 representing each plant strategy group was calculated. Then, a species was classified to that 182 dominant plant strategy group (C, S or R) for which the number of species traits was the highest 183 (e.g. if 4 traits represented C, 2 traits represented S and 6 traits represented R, then the species was 184 grouped as a ruderal (R) species). In some rare cases with same amount of traits for R and C, the 185 final strategy was selected by using the most common strategy of the overall genus. The species 
were divided into dominant plant strategy groups as follows: 71 competitors, 22 stress-tolerant and 16 ruderal species (Online Resource $\mathrm{S} 1$ ).

Although with Grime's strategy plants often possess characteristics from two or three classes, we were forced to categorize species as a single dominant class (i.e. exclusively to $\mathrm{C}, \mathrm{S}$ or $\mathrm{R}$ ) due to statistical methods used in this work (see below). Thus, all species were included in both macrophyte community composition and plant strategy variables, maintaining their comparability. Dispersal and reproduction are also acknowledged in Grime's classification, as competitive species disperse efficiently, whereas ruderal species produce vast amounts of propagules for reproduction (Grime et al., 1988). Dispersal and reproduction abilities of stress-tolerant species are low compared to $\mathrm{C}$ - and R-species.

The explanatory variables consisted of local variables, climate variables, one historical variable indicating post glaciation condition (supra- and subaquatic areas) and spatial structure (geographical coordinates). Local variables were alkalinity in water $(\mathrm{mmol} / \mathrm{l})$, total phosphorus in water $(\mu \mathrm{g} / \mathrm{l})$, water colour $(\mathrm{mg} \mathrm{Pt} / \mathrm{l})$ and lake area $\left(\mathrm{km}^{2}\right)$, whereas climate variables were comprised of growing degree days $\left(>5^{\circ} \mathrm{C}\right.$, Pirinen et al., 2012) and January temperature $\left({ }^{\circ} \mathrm{C}\right)$. Alkalinity is related to the ability of some macrophyte species to utilize bicarbonate as a source of carbon, giving these species a competitive advantage over others (Vestergaard \& Sand-Jensen, 2000). Total phosphorus reflects lakes trophic conditions (Alahuhta, 2015). Water colour is used to mirror at what water depth species can exist, as availability of light for photosynthesis decreases strongly towards deeper water columns in lakes with high humic content (Toivonen \& Huttunen, 1995). Lake area indicates horizontal habitat availability with larger lakes having more different habitats available for macrophyte establishment (Lacoul \& Freedman, 2006). Of the climate variables, growing degree 
210 days is directly related to the length and intensity of the growing season, whereas the January

211 temperature was used as a proxy for harsh winter conditions, which affect macrophytes through

212 thick ice cover, ice erosion and freezing of sediments (Hellsten, 2001; Lind et al., 2014).

213 Information on local variables was obtained from the Hertta database for the period of 2006-2011

214 (growing season only), based on mean values of 1 metre surface samples for water quality variables

215 (http://www.syke.fi/en-US/Open_information). Climate variables for lake area were derived from

216 the Finnish Meteorological Institute for the period 1981-2010 with the resolution of 1km (Pirinen et

217 al., 2012). ArcGIS 10 (ESRI, Redlands, CA, US) was used to process both climate variables. Lake

218 coordinates $(\mathrm{Y}=$ latitude, $\mathrm{X}=$ longitude) were based on centre points from each lake, gathered 219 using ArcGIS.

\section{$221 \quad$ Statistical analyses}

222 We used partial redundancy analyses (pRDA) to distinguish the relationships between variation in 223 macrophyte and explanatory variable groups. pRDAs were employed with Hellinger transformed 224 presence-absence matrices of aquatic macrophytes, because the transformation makes the data 225 analysable using linear methods (Legendre \& Gallagher, 2001). The protocol of Borcard et al. 226 (1992) was followed for pRDAs, as total variation in macrophyte variables was partitioned into 16 227 fractions: (a) pure effect of local variables, (b) pure effect of climate variables, (c) pure effect of 228 post glaciation condition, d) pure effect of geographical position (i.e. lake coordinates); and their 229 joint effects (altogether 11 joint fractions), followed by unexplained variation. The detailed 230 procedures to estimate these fractions are explained in Borcard et al. (2011).

232 Variation explained by each variable group was evaluated with adjusted $\mathrm{R}^{2}$, which provides 233 unbiased estimates of the explained variation (Peres-Neto et al., 2006). In forward selection, type I 
errors can be avoided by using adjusted $\mathrm{R}^{2}$ values, which are also comparable between different models as the number of explanatory variable is taken into account (Blanchet et al., 2008). In addition, utilization of adjusted $\mathrm{R}^{2}$ values can lead to negative pure fractions in a variation partitioning procedure (Borcard et al., 2011). For joint fractions, negative adjusted $\mathrm{R}^{2}$ values can also indicate multicollinearity among studied explanatory variables. Following the procedure of Blanchet et al. (2008), forward selection to obtain significant variables for further analysis was based on the Monte Carlo permutation test (999 permutations, $\alpha=0.05)$ and two stopping rules: $p$ > 0.05 or the adjusted $\mathrm{R}^{2}$ value of the reduced model exceeded that of the global model. Explanatory variables showed a variable degree of multicollinearity (total phosphorus and colour: $\mathrm{R}_{\text {Spearman }}=$ 0.74, $\mathrm{p}<0.001$; latitude and climate variables: $\mathrm{Rs}=|0.96-0.98|, \mathrm{p}<0.001)$, although this does not impair the variation partitioning procedure used in our study (Oksanen et al., 2012). All pRDAs were performed in the R environment with PACKFOR (S. Dray, Université Claude Bernard Lyon I) and VEGAN packages (Oksanen et al., 2012).

We also considered whether post glaciation condition had created different local environmental conditions between supra- and subaquatic lakes that further affect macrophyte community compositions. To evaluate this, we used structural equation modelling (SEM) to test a) indirect effects of post glaciation condition on water quality variables and macrophyte flora and b) direct effects of water quality on macrophytes. SEM is especially informative in studies of cause-effect relationships by investigating the networks of connections among system components (Grace et al., 2012). A key feature in SEM is to partition relationships among pathways, which traces a route from a predictor to a response representing a distinct mechanism (Grace, 2006). In our study, we built a robust SEM model among the explanatory variables and macrophyte flora that was tested separately for different macrophyte variable groups (Fig. 2). Given the rationale on the hierarchy of factors we analysed, we expected that post glaciation condition indirectly affects local water 
quality, which in turn directly influences macrophyte communities. We also assumed that water 260 quality variables were linked. We used the first two axis scores of PCA (i.e., PCA1 and PCA1) to 261 represent macrophyte community compositions. In our results, standardized coefficients indicate the 262 strength of the relationship because they are scaled to the same units (Grace et al., 2012). 263 Standardized estimates correspond to effect-size estimates. The goodness of model fit was based on 264 chi-square and the evaluation of parameter estimates on $\mathrm{z}$ statistics. The interpretation of model fit 265 is opposite to conventional statistical analysis in SEM (i.e., higher $\mathrm{p}>0.05$ indicates better model 266 based on chi-square), whereas z statistics follow the common interpretations of analysis. Our key 267 purpose was to understand the patterns of correlation among a set of variables (i.e., post glaciation 268 condition, local water quality and macrophyte community composition), not to explain as much of 269 their variance as possible with the model specified. SEM models were constructed in the R environment using LAVAAL (Rosseel, 2012) and SEMPATHS (Epskamp, 2015) packages.

\section{RESULTS}

\section{Macrophyte community compositions}

Overall variation explained in variation partitioning was $17.5 \%$ for all taxa, $17.6 \%$ for helophytes and $17.8 \%$ for hydrophytes (Table 2). Of the pure fractions, community composition of all taxa (6.6\%), helophytes (1.7\%) and hydrophytes (10.4\%) were best explained by local variables, which was the only statistically significant pure fraction. Other pure fractions had clearly smaller or nonexistence importance for all of the three macrophyte community compositions. The joint fraction of climate and geographical location was comparatively high for all taxa (6.7\%), helophytes (11.0\%) 281 and hydrophytes (4.2\%). The joint fraction of geographical location and post glaciation condition 282 also showed some explained variation for all community compositions (0.6-1.6\%), similarly to the 
joint effect of local variables and geographical location (1.2-1.4\%). Post glaciation condition and 284 geographical location were quite high compared to other fractions for helophyte community composition. These results suggest that post glaciation condition affects variation in helophyte community composition, because post glaciation condition is clearly dependent on geographical location. A majority of subaquatic lakes are located in central Finland, whereas post glaciation condition lakes span over a large area covering most of the eastern and northern parts of the country 289 (Fig. 1). Similarly, local variables vary between supra- and subaquatic lakes, as colour and total 290 phosphorus gradients are clearly wider in subaquatic lakes (Table 1). In addition, the joint 291 contribution of local variables and climate explained small amount of variation (0.9-1.1\%). The 292 number of species varied between supra- and subaquatic lakes for all taxa and helophyte community 293 compositions.

Alkalinity and colour were the most important local variables for community composition of all taxa and hydrophytes, whereas total phosphorus explained most variation for helophytes (Table 3,

Fig. 3). Of the hydrophytes, Potamogeton berctoldii and Nuphar pumila were most positively and 298 Lobellia dortmanna and Isoetes echinospora were most negatively associated with alkalinity. 299 Potamogeton natans was most positively and Subularia aquatica and Ranunculus peltatus most 300 negatively correlated with colour. Of the helophytes, Cicuta virosa was most distinctly related to 301 total phosphorus. Growing degree days of climate variables had the highest effect on all macrophyte 302 community compositions. Nuphar lutea and Nymphaea tetragona of the hydrophytes and 303 Lysimachia thyrsiflora and Phragmites australis of the helophytes were positively associated with 304 the growing degree days, which also negatively influenced the helophytes Hippuris vulgaris and the 305 hydrophytes Potamogeton perfoliatus, Potamogeton gramineus and Subularia aquatica. Of the geographical location, coordinate $\mathrm{Y}$ indicating latitudinal variation was the most important variable 
307 for all community compositions. Supra-aquatic and subaquatic lakes were quite clearly separated in 308 ordination space for all taxa and helophytes.

\section{Dominant plant strategy groups}

311 The total explained variation was $18.9 \%$ for competitive, $14.8 \%$ for stress-tolerant and $13.0 \%$ for

312 ruderal species (Table 2). Local variables were clearly the most significant pure fraction 313 contributing to all of the plant strategy groups (C: $5.4 \%, \mathrm{~S}: 9.5 \%$, R: 10.1\%). Post glaciation 314 condition affected, and the number of species clearly varied, between supra- and subaquatic lakes 315 only for competitors. Of the joint fractions, climate and geographical location influenced 316 competitive (8.1\%), stress-tolerant (4.2\%) and ruderal (2.1\%) species. For competitors, joint effects 317 of local variables and geographical location (1.7\%), local variables and climate (1.3\%) and 318 geographical location and post glaciation condition (1.8\%) also had an effect on this plant group.

Colour and alkalinity were the most important local variables for competitive species, whereas total 321 phosphorus had the highest effect on stress-tolerant and ruderal species (Table 3, Fig. 3). Among competitive species, Eleocharis mamillata and Alisma plantago-aquatica were most positively and Menyanthes trifoliata and Persicaria foliosa most negatively correlated with colour. Competitor Carex paniculata was positively associated with alkalinity. The relationship with total phosphorus was positive for ruderal Bidens cernua and negative for stress-tolerant Isoetes lacustris and ruderal Ranunculus reptans. Of climate variables, growing degree days contributed most to competitive and stress-tolerant species, and January temperature was the only climate variable selected for ruderal species. Competitors Phragmites australis and Scolochloa festucacea, and stress-tolerant Utricularia australis were positively associated with the growing degree days and January temperature. A negative relationship with these climate variables was found for competitors 
331 Ranunculus lingua, stress-tolerant Nitella flexilis and ruderal Alopecurus aequalis. Coordinate Y of 332 geographical location (i.e., latitude) was the most important variable for all plant strategy groups. 333 Post glaciation condition distinguished supra-aquatic and subaquatic lakes two their own groups for 334 competitors.

\section{Structural equation modelling}

337 The overall fit of our model was relatively poor (minimum function test statistics $=4.803$, df $=1, \mathrm{p}$ $338=0.028)$. However, we were able to compare relationships among the set of observed variables. 339 Concerning intercorrelation structure among post glaciation condition and water quality variables, 340 total phosphorus was affected by alkalinity, colour and post glaciation condition, whereas post 341 glaciation condition had no statistical influence on alkalinity and colour (Table 4). For all taxa, 342 alkalinity, colour and post glaciation condition were statistically positively significantly related to 343 macrophytes represented by the PCA2. Post glaciation condition was negatively associated with 344 helophytes in the PCA2, whereas both alkalinity (PCA1 and PCA2) and colour (PCA1) were 345 negatively correlated with hydrophytes. For competitive species, colour negatively and alkalinity 346 and post glaciation condition positively contributed to this plant group in the first and second axes, 347 respectively. Stress-tolerant plants were positively correlated with alkalinity and colour in the 348 PCA1.

\section{DISCUSSION}

352 The main purpose of our work was to investigate the relative importance of regional and local 353 determinants in explaining community composition of different macrophyte groups in high-latitude 
lakes. We found that local water quality and habitat factors greatly structured all macrophyte groups. However, climate showing a strong latitudinal gradient (through joint effect of climate and geographical location) was equally or more important for macrophyte community compositions. These findings suggest that macrophyte communities are primarily filtered by local determinants together with regional characteristics at the studied spatial scale. This finding was further supported by the (indirect) influence of post glaciation condition on local water quality variables, which in turn (directly) contributed to the macrophyte communities. We thus agree with the previous investigations (Whittaker et al., 2001; McGill, 2010; Alahuhta, 2015) that regional determinants interact with local-scale abiotic factors in explaining macrophyte community patterns and examining only regional or local factors is not sufficient for understanding how aquatic macrophyte communities are structured locally and regionally.

The environmental determinant operating at the broadest scale in our study was post glaciation condition. We expected that aquatic macrophytes with efficient dispersal strategies had evenly colonized supra- and subaquatic lakes by now (e.g., Barrat-Segretain, 1996; Sawada et al., 2003), and we indeed found few differences between strongly and poorly dispersing species (Online Resource S2). However, post glaciation condition seems to influence macrophyte community compositions after over 9000 years. We found support for this outcome from both the variation partitioning and structural equation modelling. Although the pure effect of post glaciation condition showed only a modest contribution to the macrophyte flora, the joint fraction of post glaciation condition and geographical location indicated considerable influence on macrophyte community compositions compared to most of the other joint effects. In addition, the joint contribution of local variables, post glaciation condition and geographical location suggested that these variable groups form a complex interplay with each other that is difficult to distinguish in variation partitioning. For example, the variation in colour is much wider in subaquatic lakes compared to supra lakes, 
whereas different soil types influence total phosphorus concentrations between the lakes. Finer soil

380 deposits were washed in subaquatic areas but these nutrient-rich soils are often present in supra 381 areas (Ojala et al., 2013) creating better growth conditions for plants in supra areas. On the other 382 hand, current clay soils are typically found in southern and western lowland catchments of Finland 383 as a consequence of subglacial sedimentation, enhancing natural background concentrations of 384 nutrients in subaquatic lakes (Alahuhta et al., 2011). In addition, human pressures are stronger in 385 more populated southern areas of Finland, for which anthropogenic-originated nutrients increase 386 trophic status in many subaquatic lakes (Kanninen et al., 2013b). These confounding and often 387 confronting effects make it difficult to study the effect of post glaciation condition in Finnish lakes, 388 of which most are slightly affected by human pressures.

However, structural equation modelling enabled us to distinguish the effect of post glaciation conditions on local water quality and macrophyte flora. Post glaciation condition indirectly affected macrophyte composition of all taxa, helophytes and competitors. In addition, post glaciation conditions indirectly influenced total phosphorus, which significantly structured ruderals. Helophytes were also contributed by total phosphorus, but not statistically significantly $(\mathrm{p}=0.081)$.

395 These findings suggest that aquatic macrophyte communities have, in a way similar to terrestrial plants (Skov \& Svenning, 2003), not yet reached their full distribution ranges following the last glaciation period. In addition, inorganic phosphorus can be bound in organic matter, the rise of which results in increasing colour values in water (Madsen et al., 1996). This chain of events likely explains why colour was most strongly correlated with total phosphorus (Table 4), further 400 supporting the indirect post glaciation condition effect on macrophytes. It seems colour values vary 401 along the post glaciation condition delineation in our study area. Our findings contradict previous 402 paleolimnological studies (Sawada et al., 2003; Väliranta, 2006; Väliranta et al., 2011), in which 403 aquatic macrophytes were proposed to quickly occupy ice-free areas following deglaciation. Many 
helophytes and hydrophytes classified as competitors but also stress-tolerants dispersed rapidly to 405 new habitats within a few millennia after ice sheets withdrew in North America. Furthermore, 406 aquatic macrophytes in North America responded little to post-glacial climate changes, as Late407 Holocene cooling does not appear to have affected their ranges (Dieffenbacher-Krall \& Jacobson, 408 2001). In our work, however, post glaciation condition affected mostly helophytes, because more 409 than half of the competitive species and half of ruderal species were classified as helophytes. 410 Instead, hydrophytes and stress-tolerants, of which all species were hydrophyte species, were not 411 influenced by either post glaciation condition or total phosphorus. This was also seen in the 412 ordination plots, where supra-aquatic and subaquatic lakes were distinguished from each other for 413 all taxa, helophyte and competitors only. Helophytes often inhabit aquatic-terrestrial ecotones, 414 where growing conditions in many ways resemble that of terrestrial ecosystems (Alahuhta et al., 415 2011). Thus, it may be that true aquatic macrophytes growing permanently in water are less 416 influenced by post glaciation condition than semi-aquatic helophyte species.

Climate structured aquatic macrophyte communities at the second broadest scale. Latitudinal 419 gradient in climate is strong in the boreal region and previous studies have evidenced a clear 420 variation in species distributions along a changing climate from south to north (Rørslett, 1991; 421 Heino \& Alahuhta, 2015; Alahuhta et al., 2016). Climate was equally or more important than other factors for community composition of all taxa, helophytes and competitors. The two regional factors (climate and glaciation) are also linked through latitudinal and altitudinal variation, as supraaquatic lakes are located in more northern and eastern areas with lower growing degree days and more continental climate conditions (Alahuhta et al., 2011). In addition, supra-aquatic lakes are typically at least 200m above sea level (Tikkanen \& Oksanen, 2002), where temperatures are lower compared to lowland areas. Competitive species were generally dominant in sub-aquatic lakes with 
428 higher nutrient status, thus supporting the original theory of Grime (1977) regarding resource 429 availability.

431 Of individual climate variables, growing degree days had the greatest influence on the community 432 composition of all taxa, helophytes, hydrophytes, competitors and stress-tolerants. Similar findings 433 have been evidenced for aquatic macrophytes in other studies (Alahuhta et al., 2011; Alahuhta et 434 al., 2016). Coordinate $\mathrm{Y}$, which similarly to growing degree days mirrors broad-scale latitudinal 435 variation in climate, contributed most to all community compositions. The species associated most 436 strongly with latitudinal climate gradient (Nuphar lutea, Lysimachia thyrsiflora and Phragmites 437 australis) are absent from the most northern parts of Finland (Lampinen et al., 2015). The 438 relationship was negative for the hydrophytes Subularia aquatica and Potamogeton gramineus, 439 which have more northern distributions (Lampinen et al., 2015). On the other hand, January 440 temperatures affected most ruderals but also all taxa, helophytes and competitors. The influence of 441 harsh winter conditions on macrophytes is difficult to distinguish from the latitudinal climate 442 gradient, however, as the temperature of January and growing degree days were highly correlated. 443 Harsh winter conditions, such as ice erosion and freezing of littoral sediments, should especially 444 structure stress-tolerant species, of which many large-sized isoetids are vulnerable to these harmful 445 phenomena (Lind et al., 2014). However, ice effect is most obvious in lakes with regulated water 446 level, and therefore not visible in research lakes, where distribution of large sized isoetids is 447 determined by water quality (Hellsten, 2001).

449 Local variables contributed to the macrophyte flora at the smallest spatial scale. The high influence 450 of local determinants on macrophyte flora originates from the fact that variation in local gradients is 451 typically very wide in freshwater ecosystems, creating variable habitat conditions even in 
neighbouring lakes (Elser et al., 2007). Wide water quality gradients have enabled species with

453 different tolerances to local environmental conditions to co-exist in geographically closely-situated 454 habitats, typically resulting in relatively high species turnover among these habitats for aquatic macrophytes (Alahuhta \& Heino, 2013; Viana et al., 2014). In addition, regional factors have had a smaller impact on freshwater assemblages due to the sheltering effect of water, which has, for example, moderated the influence of extreme atmospheric temperatures on aquatic species (Lacoul \& Freedman, 2006). Although the climate gradient in freshwater ecosystems is not as wide as in terrestrial systems, climatic determinants must be studied alongside local factors when investigating aquatic macrophyte community compositions at the regional scale.

Alkalinity of individual local variables was the most important local variable for community composition of all taxa and hydrophytes. Competitors were also greatly affected by alkalinity. The effect of alkalinity is related to the different forms of carbon used by aquatic plants in photosynthesis. Concentrations of carbon dioxide are typically low in water; however, some macrophyte species, which are mostly hydrophytes, can utilize bicarbonate as a source of carbon (Capers et al., 2010; Alahuhta \& Heino, 2013). We found that hydrophytes Potamogeton berchtoldii and Nuphar pumila were most positively associated with alkalinity. Vestergaard \& Sand-Jensen (2000) categorized P. berchtoldii to be present in alkaline lakes and N. pumila and $C$.

471 productivity (Toivonen \& Huttunen, 1995). Colour was an equally important local peatland 472 richness-related variable for all taxa and hydrophyte compositions, as also reported for other boreal 473 hydrophyte community compositions (Alahuhta et al., 2013; Kanninen et al., 2013b). Colour mirrors water transparency and growth of submerged macrophytes is limited to shallow littoral areas in dark-water, humic lakes (Toivonen \& Huttunen, 1995; Hellsten, 2001). In our work, 
For helophytes, total phosphorus reflects trophic status in lakes, with Cicuta virosa and Carex acuta

most greatly benefitting from increased nutrient concentrations. Lemna minor also had a positive relationship with total phosphorus, whereas Ranunculus reptans and Isoetes lacustris were negatively associated with phosphorus concentration. Lemna species favour lakes with high trophic status and isoetids are known to suffer from an enrichment of nutrients in water, which further results in lowered light availability and increased organic sedimentation (Rorslett, 1991; Borman et 483 al., 2009).

Finally, the hierarchical nature of regional and local determinants in structuring aquatic macrophyte community compositions found in our study is also related to the accuracy of explanatory variables. Local factors were measured at the lake level corresponding with that of macrophyte surveys. 488 Climate determinants were similarly delineated to lake surface area, but fine-scale variation in 489 climate gradient is modest (Whittaker et al., 2001). Both local water quality and climate factors 490 were long-term averages of multiple measurements, decreasing uncertainty related to yearly 491 changes in these observations. Separation of supra- and subaquatic areas was the least exact based 492 on the modelled scenario, however, the accuracy is well-suited for our regional study scale covering 493 almost $300000 \mathrm{~km}^{2}$.

\section{ACKNOWLEDGEMENTS}

We are highly thankful for two reviewers for their fair and constructive comments, which clearly improved our work. We also thank Joseph Bailey for helping with the structural equation modelling. The project was partly supported by Biological Monitoring of Finnish Freshwaters under the diffuse loading project (XPR3304) financed by the Ministry of Agriculture and Forestry and partly by the national surveillance monitoring programmes of lakes. We thank the numerous field 
501 teams who participated in the field work. Seppo Hellsten was supported by the EU-funded MARS 502 project (7th EU Framework Programme, Theme 6., Contract No.: 603378). Language of the 503 manuscript was checked by Aaron Bergdahl.

\section{REFERENCES}

Alahuhta, J., K.-M. Vuori \& M. Luoto, 2011. Land use, geomorphology and climate as environmental determinants of emergent aquatic macrophytes in boreal catchments. Boreal Environment Research 16: 185-202.

Alahuhta, J., A. Kanninen \& K.-M. Vuori, 2012. Response of macrophyte communities and status metrics to natural gradients and land use in boreal lakes. Aquatic Botany 103: 106-114.

Alahuhta, J. \& J. Heino, 2013. Spatial extent, regional specificity and metacommunity structuring in lake macrophytes. Journal of Biogeography 40: 1572-1582.

Alahuhta, J., A. Kanninen, S. Hellsten, K.-M. Vuori, M. Kuoppala \& H. Hämäläinen, 2013. Environmental and spatial correlates of community composition, richness and status of boreal lake macrophytes. Ecological Indicators 32: 172-181.

Alahuhta, J., A. Kanninen, S. Hellsten, K.-M. Vuori, M. Kuoppala \& H. Hämäläinen 2014. Variable response of functional macrophyte groups to lake characteristics, land use and space: implications for bioassessment. Hydrobiologia 737: 201-214. regional scale. Journal of Vegetation Science 26: 564-575. 
Alahuhta, J., J. Rääpysjärvi, S. Hellsten, M. Kuoppala \& J. Aroviita 2015. Species sorting drives variation of boreal lake and river macrophyte communities. Community Ecology 16: 76-85.

Alahuhta, J., J. Halmetoja, H. Tukiainen \& J. Hjort, 2016. Importance of spatial scale in structuring emergent lake vegetation across environmental gradients and scales: GIS-based approach. Ecological Indicators 60: 1164-1172.

Barrat-Segretain, M.H., 1996. Strategies of reproduction, dispersion, and competition in river plants: A review. Vegetatio 123: 13-37.

Blanchet, F.G., P. Legendre \& D. Borcard, 2008. Forward selection of explanatory variables. Ecography 89: 2623-2632.

Borcard, D., P. Legendre \& P. Drapeau, 1992. Partialling out the spatial component of ecological variation. Ecology 73: 1045-1055.

Borcard, D., F. Gillet \& P. Legendre, 2011. Numerical ecology with R. Springer, NewYork, NY, US.

Borman, S.C., S.M. Galatowitsch \& R.M. Newman, 2009. The effects of species immigrations and changing conditions on isoetid communities. Aquatic Botany 91: 143-150.

Capers, R.S., R. Selsky \& G.J. Bugbee, 2010. The relative importance of local conditions and regional processes in structuring aquatic plant communities. Freshwater Biology 55: 952-966.

Claussen, P., B.A. Nolet, A.D. Fox \& M. Klaassen, 2002. Long-distance endozoochorous dispersal of submerged macrophyte seeds by migratory waterbirds in northern Europe - a critical review of possibilities and limitations. Acta Oecologia 23: 191-203.

De Bie, T., L. De Meester, L. Brendonck, K. Martens, B. Goddeeris, D. Ercken, H. Hampel, L. Denys, L. Vanhecke, K. Van der Gucht, J. Van Wichelen, W. Vyverman \& S.A.J. Declerck, 
2012. Body size and dispersal mode as key traits determining metacommunity structure of aquatic organisms. Ecology Letters 15: 740-747.

Dieffenbacher-Krall, A.C. \& G.L. Jacobson, 2001. Post-glacial changes in the geographic ranges of certain aquatic vascular plants in North America. Proceeding of the Royal Irish Academy B 101: 79-84.

Elser, J.J., M.E.S. Bracken, E.E. Cleland, D.S. Gruner, W S. Harpole, H. Hillebrand, J.T. Ngai, E.W. Seabloom, J.B. Shurin \& J.E. Smith, 2007. Global analysis of nitrogen and phosphorus limitation of primary producers in freshwater, marine and terrestrial ecosystems. Ecology Letters 10: 1135-1142.

Eronen, M., 2005. Land Uplift: Virgin Land from the Sea. In: Seppälä, M. (Ed.), The Physical Geography of Fennoscandia. Oxford University Press, Oxford, pp. 17-34.

Epskamp, S., 2015. semPlot: Unified Visualizations of Structural Equation Models, Structural Equation Modeling: A Multidisciplinary Journal, DOI: 10.1080/10705511.2014.937847.

Grace, J.B., 2006. Structural Equation Modeling and Natural Systems. Cambridge University Press.

Grace, J.B., D.R. Jr. Schoolmaster, G.R. Guntenspergen, A.M. Little, B.R. Mitchell, K.M. Miller \& E.W. Schweiger, 2012. Guidelines for a graph-theoretic implementation of structural equation modeling. Ecosphere 3: 1-44.

Grime, J.P. 1977. Evidence for the Existence of Three Primary Strategies in Plants and Its Relevance to Ecological and Evolutionary Theory. The American Naturalists 111: 1169-1194.

Grime, J.P., J.G. Hodgson \& R. Hunt, 1988. Comparative Plant Ecology. A Functional Approach to Common British Species. 
565 Heino, J. \& H. Toivonen, 2008. Aquatic plant biodiversity at high latitudes: patterns of richness and rarity in Finnish freshwater macrophytes. Boreal Environment Research 13: 1-14.

Heino, J., J. Soininen, J. Alahuhta, J. Lappalainen \& R. Virtanen, 2015. A comparative analysis of metacommunity types in the freshwater realm. Ecology and Evolution 5: 1525-1537.

Heino, J. \& J. Alahuhta, 2015. Elements of regional beetle faunas: faunal variation and compositional breakpoints along climate, land cover and geographical gradients. Journal of Animal Ecology 84: 427-441.

Hellsten, S., 2001. Effects of lake water level regulation on aquatic macrophyte stands in northern Finland and options to predict these impacts under varying conditions. Acta Botanica Fennica 171: $1-47$.

Jalas, J., 1958. Suuri Kasvikirja I. Otava, Keuruu.

Jalas, J., 1965. Suuri Kasvikirja II. Otava, Keuruu.

Jalas, J., 1980. Suuri Kasvikirja III. Otava, Keuruu.

Kanninen, A., V.-M. Vallinkoski, L. Leka, T.J. Marjomäki, S. Hellsten \& H. Hämäläinen, 2013a. A comparison of two methods for surveying aquatic macrophytecommunities in boreal lakes: implications for bioassessment. Aquatic Botany 104: 88-103.

Kanninen, A., Hellsten, S. \& H. Hämäläinen, 2013b. Comparing stressor-specific indices and general measures of taxonomic composition for assessing the status of boreal lacustrine macrophyte communities. Ecological Indicators 27: 29-43

Koch, P.L. \& A.D. Barnosky, 2006. Late quaternary extinctions: State of the debate. Annual Review of Ecology, Evolution and Systematics 37: 215-250. 
Lacoul, P. \& B. Freedman, 2006. Environmental influences on aquatic plants in freshwater ecosystems. Environmental Reviews 14: 89-136.

Lampinen, R., T. Lahti \& M. Heikkinen, 2015. Plant atlas of Finland 2014. University of Helsinki, The Finnish Museum of Natural History, Botanical Museum, Helsinki

Legendre, P. \& E.D. Gallagher, 2001. Ecologically meaningful transformations for ordination of species data. Oecologia 129: 271-280.

Lind, L., C. Nilsson, L.E. Polvi \& C. Weber, 2014. The role of ice dynamics in shaping vegetation in flowing waters. Biological Reviews 89: 791-804.

Madsen, T.V., S.C. Maberly \& G. Bowes, 1996. Photosynthetic acclimation of submersed angiosperms to $\mathrm{CO}_{2}$ and $\mathrm{HCO}_{3}{ }^{-}$. Aquatic Botany 53: 15-30.

McCann, M.J., 2015. Local and regional determinants of an uncommon functional group in freshwater lakes and ponds. PLoS ONE 10: e0131980.

McGill, B.J. 2010. Matters of Scale. Science 328: 575-576.

Murphy, K.J., B. Rørslett \& I. Springuel, 1990. Strategy Analysis of Submerged Lake Macrophyte Communities: an International Example. Aquatic Botany 36: 303-323.

Ojala, A.E.K., J.-P. Palmu, A. Åberg, S. Åberg \& H. Virkki, 2013. Development of an ancient shoreline database to reconstruct the Litorina Sea maximum extension and the highest shoreline of the Baltic Sea basin in Finland. Bulletin of the Geological Society of Finland 85: $126-144$.

Oksanen, J., F.G. Blanchet, R. Kindt, P. Legendre, P.R. Minchin, R.B. O’Hara, G.L. Simpson, P. Solymos, M.H.H. Stevens \& H. Wagner, 2012. vegan: community ecology package. R package version 2.0-3. Available at: http://CRAN.R-project.org/package=vegan. 
608 Peres-Neto, P.R., P. Legendre, S. Dray \& D. Borcard, 2006. Variation partitioning of species data 609 matrices: estimation and comparison of fractions. Ecology 87: 2614-2625.

610 Pirinen, P., H. Simola, J. Aalto, J.P. Kaukoranta, P. Karlsson \& R. Ruuhela, 2012. Climatological statistics of Finland 1981-2010. Finnish Meteorological Institute Reports 25, Helsinki.

Ricklefs, R.E., 2004. A comprehensive framework for global patterns in biodiversity. Ecology Letters 7: 1-15.

Rosseel, Y., 2012. lavaan: An R Package for Structural Equation Modeling. Journal of Statistical Software 48: 1-36

Rørslett, B. 1991. Principal determinants of aquatic macrophyte species richness in northern

Rørslett, B., 1989. An integrated approach to hydropower impact assessment. II. Submerged macrophytes in some Norwegian hydro-electric lakes. Hydrobiologia 175: 65-82.

Sawada, M., A.E. Viau \& K. Gajewski, 2003. The biogeography of aquatic macrophytes in North America since the Last Glacial Maximum. Journal of Biogeography 30: 999-1017.

Soininen, J., 2014. A quantitative analysis of species sorting across organisms and ecosystems. Ecology 95: 3284-3292. overlooked dispersal pathway for a broad spectrum of plant species. Journal of Ecology 104: 443-455. 
Svenning, J.-C., 2003. Deterministic Plio-Pleistocene extinctions in the European cool-temperate tree flora. Ecology Letters 6: 646-653.

Svenning, J.-C. \& Skov, F. (2003) Could the tree diversity pattern in Europe be generated by postglacial dispersal limitation? Ecology Letters, 10, 453-460.

Svenning, J.-C., M.C. Fitzpatrick, S. Normand, C.H. Graham, P.B. Pearman, L.R. Iverson \& F. Skov., 2010. Geography, topography, and history affect realized-to-potential tree species richness patterns in Europe. Ecography 33: 1070-1080.

Tikkanen, M. \& J. Oksanen, 2002. Late Weichselian and Holocene shore displacement history of the Baltic Sea in Finland. Fennia 180: 1-2: 9 - 20.

Toivonen, H. \& P. Huttunen, 1995. Aquatic macrophytes and ecological gradients in 57 small lakes in southern Finland. Aquatic Botany 51: 197-221.

Vestergaard, O. \& K. Sand-Jensen, 2000. Aquatic macrophyte richness in Danish lakes in relation to alkalinity, transparency, and lake area. Canadian Journal of Fisheries and Aquatic Sciences 57: 2022-2031.

Viana, D.S., L. Santamaría, K. Schwenk, M. Manca, A. Hobæk, M. Mjelde, C. D. Preston, R. J. Gornall, J. M. Croft, R. A. King, A. J. Green \& J. Figuerola, 2014. Environment and biogeography drive aquatic plant and cladoceran species richness across Europe. Freshwater Biology 59: 2096-2106.

Väliranta, M., 2006. Long-term changes in aquatic plant species composition in North-eastern European Russia and Finnish Lapland, as evidenced by plant macrofossil analysis. Aquatic Botany 85: 224-232. 
651 Välinranta, M., J. Weckström, S. Siitonen, H. Seppä, J. Alkio, S. Juutinen \& E.-S. Tuittila, 2011. Holocene aquatic ecosystem change in the boreal vegetation zone of northern Finland. Journal of Paleolimnology 45: 339-352.

654 Whittaker, R.J., K.J. Willis \& R. Field, 2001. Scale and species richness: towards a general, 655 hierarchical theory of species diversity. Journal of Biogeography 28: 453-470.

656 Willis, K. J. \& R.J. Whittaker, 2002. Species diversity -scale matters. Science 295: 1245-1248.

672 Table 1. Descriptive statistics of explanatory variables and number of species in supra- and 673 subaquatic lakes. 


\begin{tabular}{|c|c|c|c|c|}
\hline & & Supra & Sub & Total \\
\hline \multicolumn{5}{|c|}{ Environmental (local) variables } \\
\hline \multirow[t]{3}{*}{ Alkalinity (mmol/l) } & Mean & 0.16 & 0.19 & 0.18 \\
\hline & Min. & 0.02 & 0.04 & 0.02 \\
\hline & Max. & 0.88 & 0.68 & 0.88 \\
\hline \multirow[t]{3}{*}{ Total phosphorus $(\mu \mathrm{g} / \mathrm{l})$} & Mean & 14.1 & 26.5 & 20.3 \\
\hline & Min. & 4.0 & 2.6 & 2.6 \\
\hline & Max. & 39.1 & 131.2 & 131.2 \\
\hline \multirow[t]{3}{*}{ Colour mg (Pt/l) } & Mean & 72 & 83 & 77 \\
\hline & Min. & 14 & 3 & 3 \\
\hline & Max. & 155 & 270 & 270 \\
\hline \multirow[t]{3}{*}{ Lake area $\left(\mathrm{km}^{2}\right)$} & Mean & 9.3 & 8.4 & 8.9 \\
\hline & Min. & 0.5 & 0.7 & 0.5 \\
\hline & Max. & 55.9 & 85.6 & 85.6 \\
\hline \multirow[t]{3}{*}{ Growing degree days $\left(>5^{\circ} \mathrm{C}\right)$} & Mean & 1016 & 1169 & 1093 \\
\hline & Min. & 538 & 839 & 538 \\
\hline & Max. & 1348 & 1430 & 1430 \\
\hline \multirow[t]{3}{*}{ January temperature $\left({ }^{\circ} \mathrm{C}\right)$} & Mean & -11.1 & -9.5 & -10.3 \\
\hline & Min. & -13.8 & -13.1 & -13.8 \\
\hline & Max. & -5.4 & -6.3 & -5.4 \\
\hline \multicolumn{5}{|l|}{ Number of species } \\
\hline \multirow[t]{3}{*}{ All taxa } & Mean & 22.6 & 28.4 & 25.5 \\
\hline & Min. & 9 & 14 & 9 \\
\hline & Max. & 39 & 55 & 55 \\
\hline \multirow[t]{3}{*}{ Hydrophytes } & Mean & 13.3 & 14.1 & 13.7 \\
\hline & Min. & 4 & 5 & 4 \\
\hline & Max. & 25 & 25 & 25 \\
\hline \multirow[t]{3}{*}{ Helophytes } & Mean & 9.3 & 14.3 & 11.8 \\
\hline & Min. & 2 & 6 & 2 \\
\hline & Max. & 18 & 30 & 30 \\
\hline \multirow[t]{3}{*}{ Competitors } & Mean & 15.7 & 21.8 & 18.7 \\
\hline & Min. & 2 & 10 & 2 \\
\hline & Max. & 27 & 43 & 43 \\
\hline \multirow[t]{3}{*}{ Stress-tolerant } & Mean & 5.3 & 4.8 & 5.1 \\
\hline & Min. & 0 & 1 & 0 \\
\hline & Max. & 10 & 10 & 10 \\
\hline \multirow[t]{3}{*}{ Ruderal } & Mean & 1.5 & 1.8 & 1.7 \\
\hline & Min. & 0 & 0 & 0 \\
\hline & Max. & 5 & 7 & 7 \\
\hline
\end{tabular}

676 Table 2. Results of variation partitioning as percentage value (*100) based on adjusted $\mathrm{R}^{2}$ values 677 and forward selection using the procedure of Blanchet et al. (2008). Statistically significant (p < 
678 0.05) pure fractions based on the ANOVA-like permutation test are marked in italics. "_" indicate

679 negative adjusted $\mathrm{R}^{2}$ values. $\mathrm{C}=$ competitors, $\mathrm{S}=$ stress-tolerants, $\mathrm{R}=$ ruderals.

\begin{tabular}{lllllll}
\hline & $\begin{array}{l}\text { All } \\
\text { Taxa }\end{array}$ & Helophytes & Hydrophytes & C & S & R \\
\hline Local & 6.63 & 1.69 & 10.43 & 5.39 & 9.54 & 10.05 \\
Climate & - & 0.38 & 0.06 & 0.23 & 0.12 & 0.05 \\
Supra & 0.01 & 0.08 & 0.34 & 0.02 & 0.00 & 0.00 \\
XY & - & 0.47 & - & 0.07 & 0.05 & - \\
Local+Climate & 1.05 & 0.87 & 0.92 & 1.27 & 0.71 & 0.33 \\
Local+Supra & - & - & - & - & 0.00 & 0.00 \\
Local+XY & 1.38 & 1.17 & 1.31 & 1.65 & 1.10 & 0.55 \\
Climate+Supra & 0.90 & 0.96 & 0.66 & 1.28 & 0.00 & 0.00 \\
Climate+XY & 6.77 & 11.03 & 4.18 & 8.09 & 4.17 & 2.07 \\
Supra+XY & 1.30 & 1.62 & 0.56 & 1.83 & 0.00 & 0.00 \\
Local+Climate+Supra & 0.63 & 1.03 & 0.48 & 0.68 & 0.00 & 0.00 \\
Local+Climate+XY & - & - & - & - & - & 0.11 \\
Local+Supra+XY & 0.71 & 1.36 & 0.46 & 0.74 & 0.00 & 0.00 \\
Climate+Supra+XY & - & - & 0.07 & - & 0.00 & 0.00 \\
All four groups & - & - & - & - & 0.00 & 0.00 \\
\hline
\end{tabular}

680

681

682

683

684

685

686

687

688

689

690

691

692 
693

694

695 
Table 3. The most important explanatory variables explaining aquatic macrophyte communities of all taxa, helophytes and hydrophytes and three plant strategy groups (competitors, stress-tolerant and ruderal) derived from Grime's categorization. The variables were selected based on adjusted $\mathrm{R}^{2}$ and forward selection using the Monte Carlo permutation test (999 permutations; $\mathrm{a}=0.05$ ). GDD = growing degree days, $\mathrm{Y}=$ latitude, $\mathrm{X}=$ longitude. Statistical level of significance: $*<0.05 ; * *<0.01 ; * * * 0.001$.

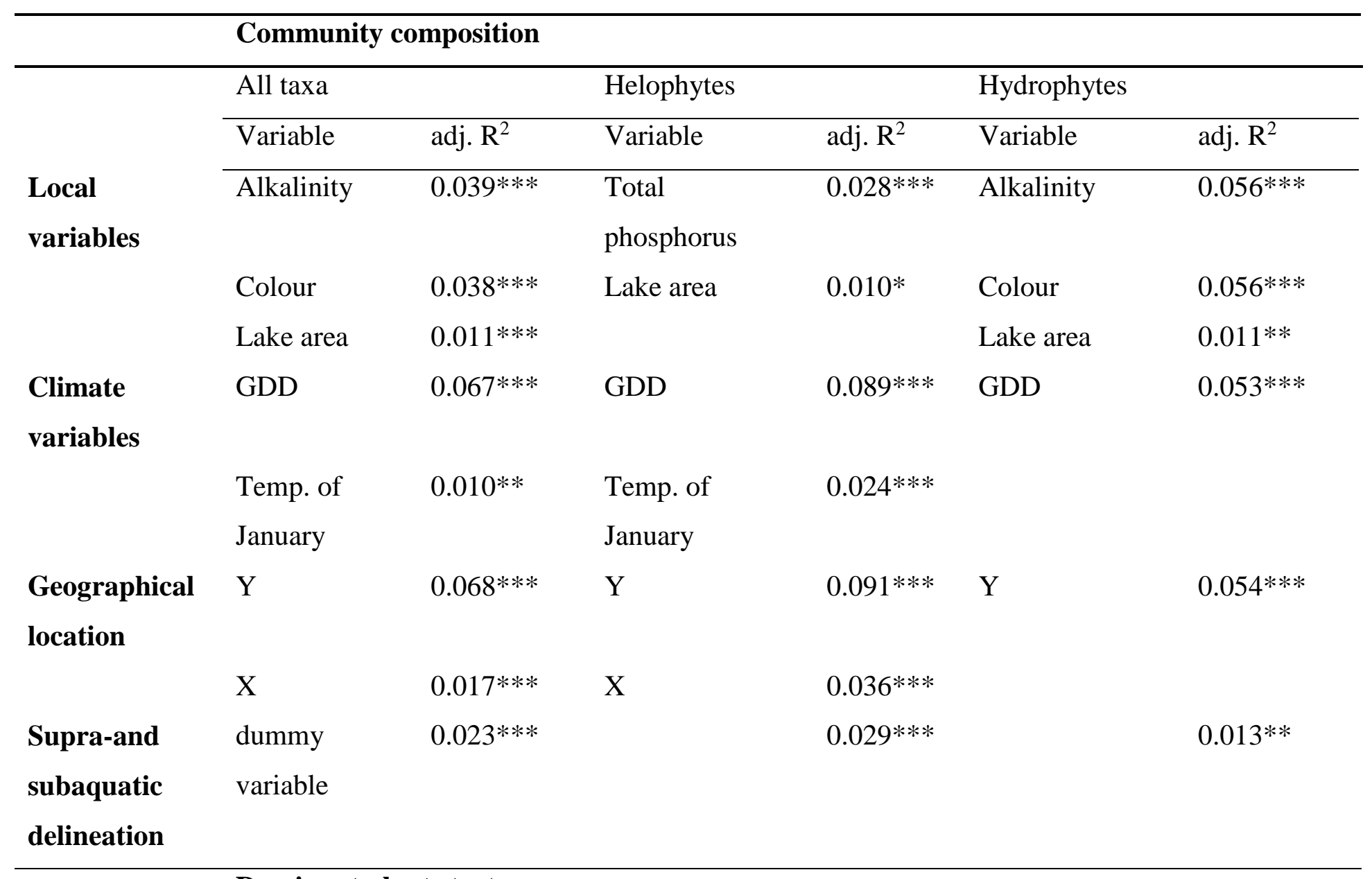

Dominant plant strategy group 


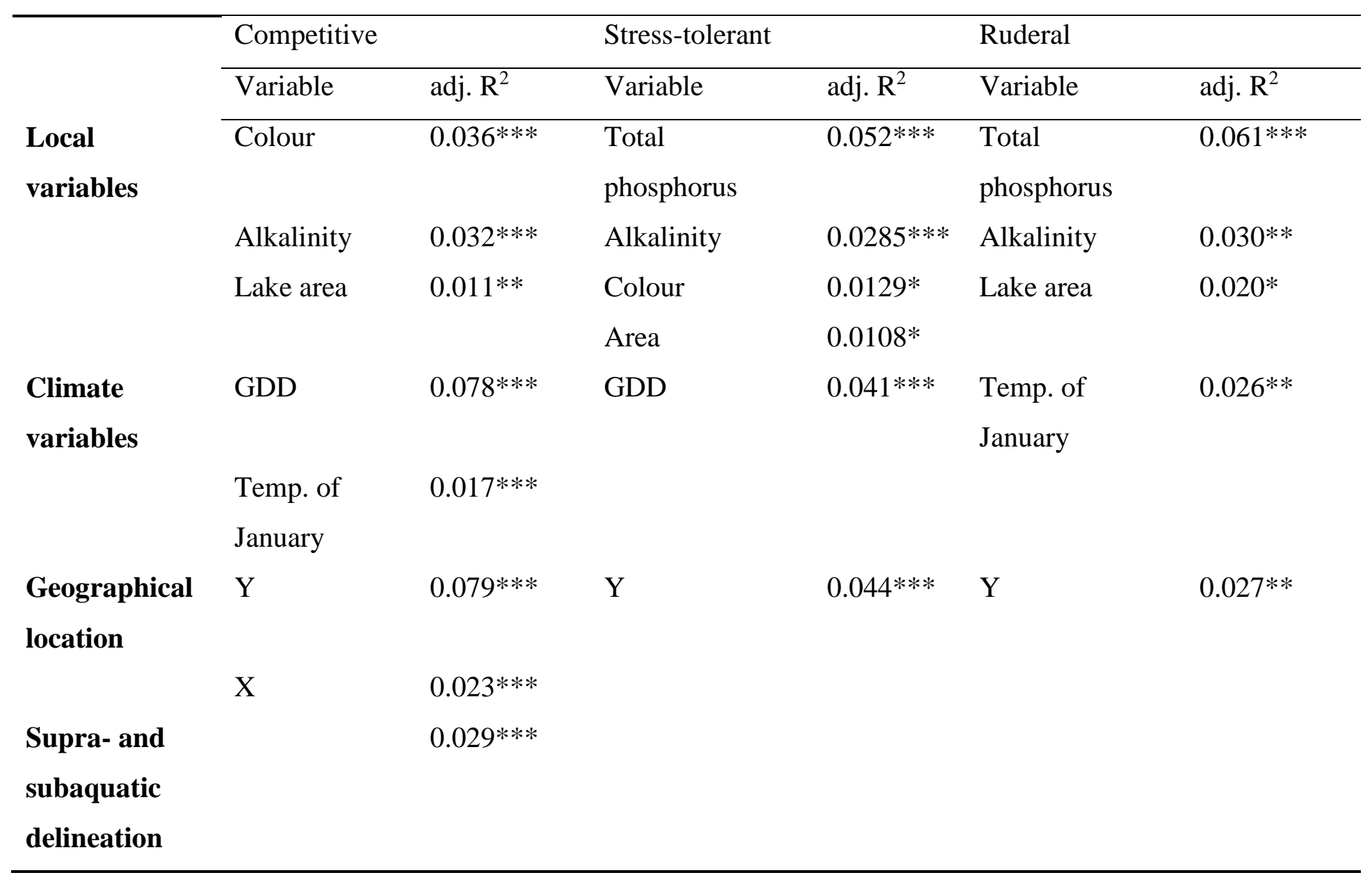


Table 4. Standardized parameter estimates as weighted edges from structural equation modelling (SEM) among post glaciation condition (supra), local water quality and macrophyte community composition of different variable groups, which were represented by the first two axis scores of principal redundancy analysis (PCA1 and PCA2). A suggested guideline for interpreting the influence of standardized path coefficients with absolute values is that less than 0.10 indicates a small effect, values around 0.30 indicate a medium effect and values greater than 0.50 indicate a large effect (e.g., Grace, 2006). The a priori hypothesized model is given in Fig. 2. “ $\rightarrow$ ”: direct effect, “( $\rightarrow$ )”: indirect effect, TP: total phosphorus, PGC: post glaciation condition originated from the delineation between supra- and subaquatic lakes. Statistical level of significance: $*<0.05 ; * *<0.01 ; * * *<0.001$.

\begin{tabular}{|c|c|c|c|c|c|c|}
\hline & PCA1 & & & & & \\
\hline Interactions & All taxa & Helophytes & Hydrophytes & Competitors & Stressors & Ruderals \\
\hline Alkalinity $\rightarrow \mathrm{TP}$ & $0.444 * * *$ & $0.444 * * *$ & $0.444 * * *$ & $0.444 * * *$ & $0.444 * * *$ & $0.444 * * *$ \\
\hline Color $\rightarrow \mathrm{TP}$ & $0.650 * * *$ & $0.650 * * *$ & $0.650 * * *$ & $0.650 * * *$ & $0.650 * * *$ & $0.650 * * *$ \\
\hline PGC $(\rightarrow)$ TP $\rightarrow$ Macrophytes & $0.167 * * \mid-0.158$ & $0.167 * * \mid-0.186$ & $0.167 * * \mid 0.109$ & $0.167 * * \mid 0.166$ & $0.167 * * \mid 0.110$ & $\begin{array}{l}0.167 * * \mid 0.379 * * * \\
\end{array}$ \\
\hline PGC $(\rightarrow)$ Alkalinity $\rightarrow$ Macrophytes & $0.096 \mid-0.258$ & $0.096 \mid-0.146$ & $0.096 \mid 0.458 * * *$ & $0.096 \mid 0.173$ & $0.096 \mid 0.454 * * *$ & $0.096 \mid 0.206$ \\
\hline PGC $(\rightarrow)$ Color $\rightarrow$ Macrophytes & $0.101 \mid 0.216$ & $0.101 \mid 0.177$ & $0.101 \mid 0.558 * * *$ & $0.101 \mid-0.374^{*}$ & $0.101 \mid 0.367 * *$ & $0.101 \mid-0.022$ \\
\hline \multirow[t]{2}{*}{ PGC $(\rightarrow)$ Macrophytes } & 0.104 & 0.022 & 0.001 & -0.100 & -0.038 & -0.107 \\
\hline & PCA2 & & & & & \\
\hline Alkalinity $\rightarrow \mathrm{TP}$ & $0.444 * * *$ & $0.444 * * *$ & $0.444 * * *$ & $0.444 * * *$ & $0.444 * * *$ & $0.444 * * *$ \\
\hline Color $\rightarrow \mathrm{TP}$ & $0.650 * * *$ & $0.650 * * *$ & $0.650 * * *$ & $0.650 * * *$ & $0.650 * * *$ & $0.650 * * *$ \\
\hline PGC $(\rightarrow) \mathrm{TP} \rightarrow$ Macrophytes & 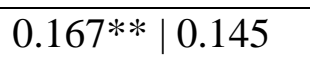 & $0.167 * * \mid-0.280$ & $0.167 * * \mid 0.095$ & $0.167 * * \mid 0.131$ & $0.167 * * \mid 0.055$ & $0.167 * * \mid-0.119$ \\
\hline PGC $(\rightarrow)$ Alkalinity $\rightarrow$ Macrophytes & $0.096 \mid 0.472 * * *$ & \begin{tabular}{ll|l}
0.096 & -0.141
\end{tabular} & $0.096 \mid 0.462 * * *$ & $0.096 \mid 0.328 * *$ & $0.096 \mid 0.059$ & $0.096 \mid 0.073$ \\
\hline PGC $(\rightarrow)$ Color $\rightarrow$ Macrophytes & $0.101 \mid 0.354 * * *$ & $0.101 \mid-0.045$ & \begin{tabular}{l|l|l|l}
0.101 & -0.233
\end{tabular} & $0.101 \mid 0.138$ & $0.101 \mid 0.209$ & $0.101 \mid 0.267$ \\
\hline PGC $(\rightarrow)$ Macrophytes & $0.309 * * *$ & $-0.382 * * *$ & -0.090 & $0.516 * * *$ & 0.042 & 0.173 \\
\hline
\end{tabular}





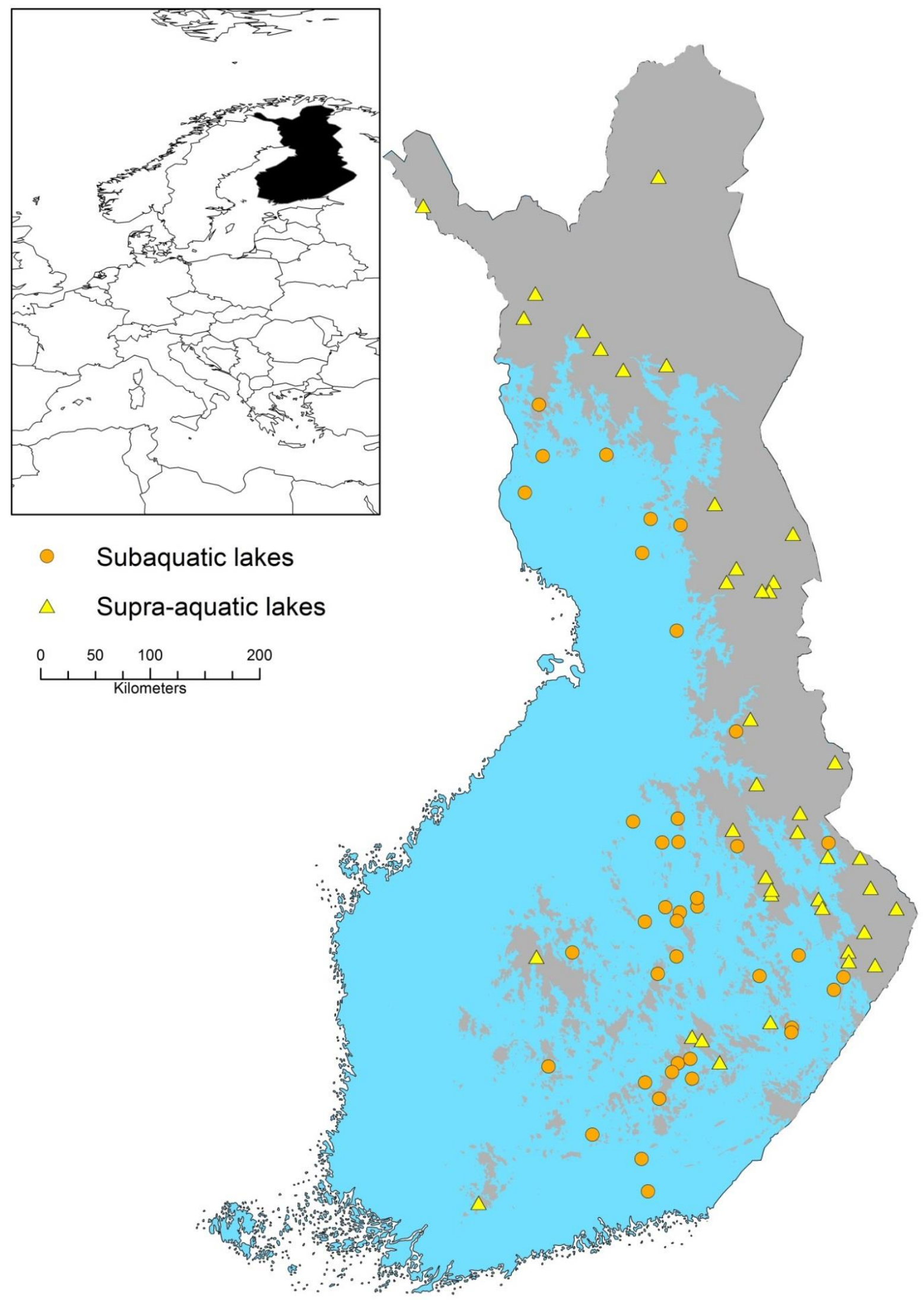

Fig. 1. Location of supra- and subaquatic lakes in Finland. 


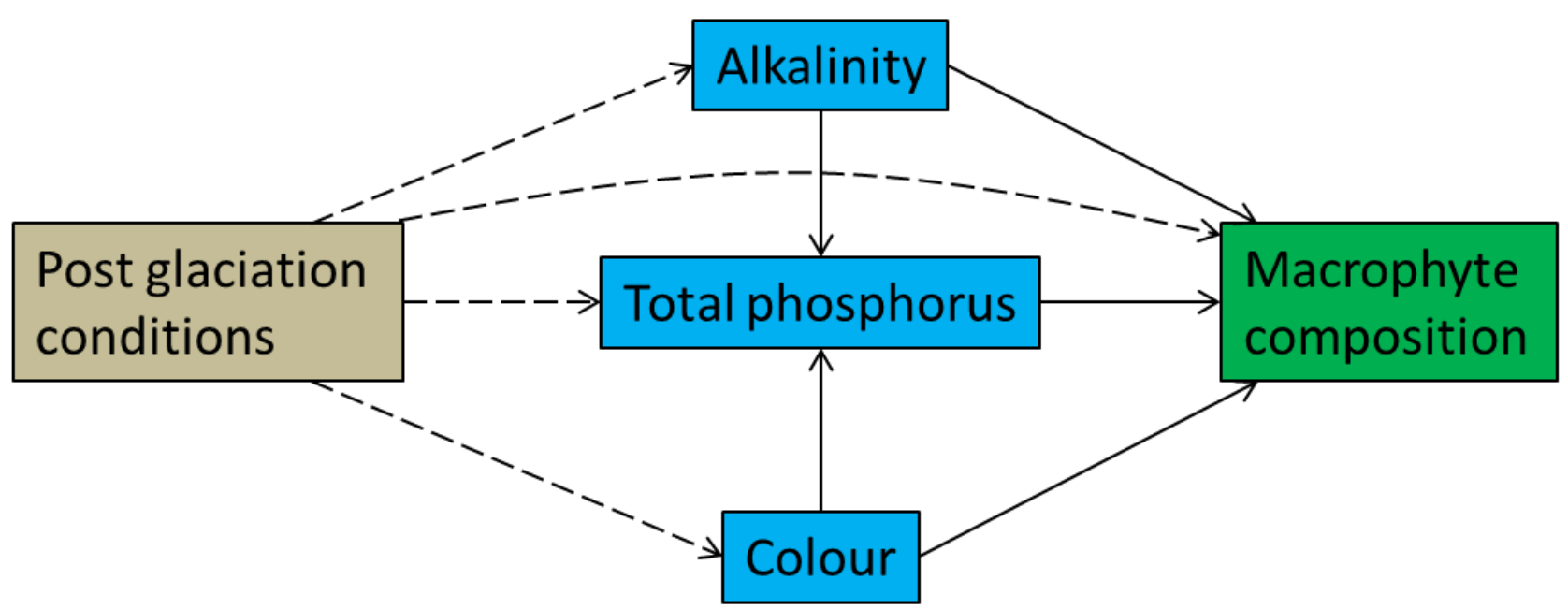

Fig. 2. Conceptual model used to evaluate the influence of post glaciation condition on local variables and macrophyte community composition using structural equation modelling. Dashed lines indicate indirect, endogenous effect, whereas full lines indicate direct influence. 

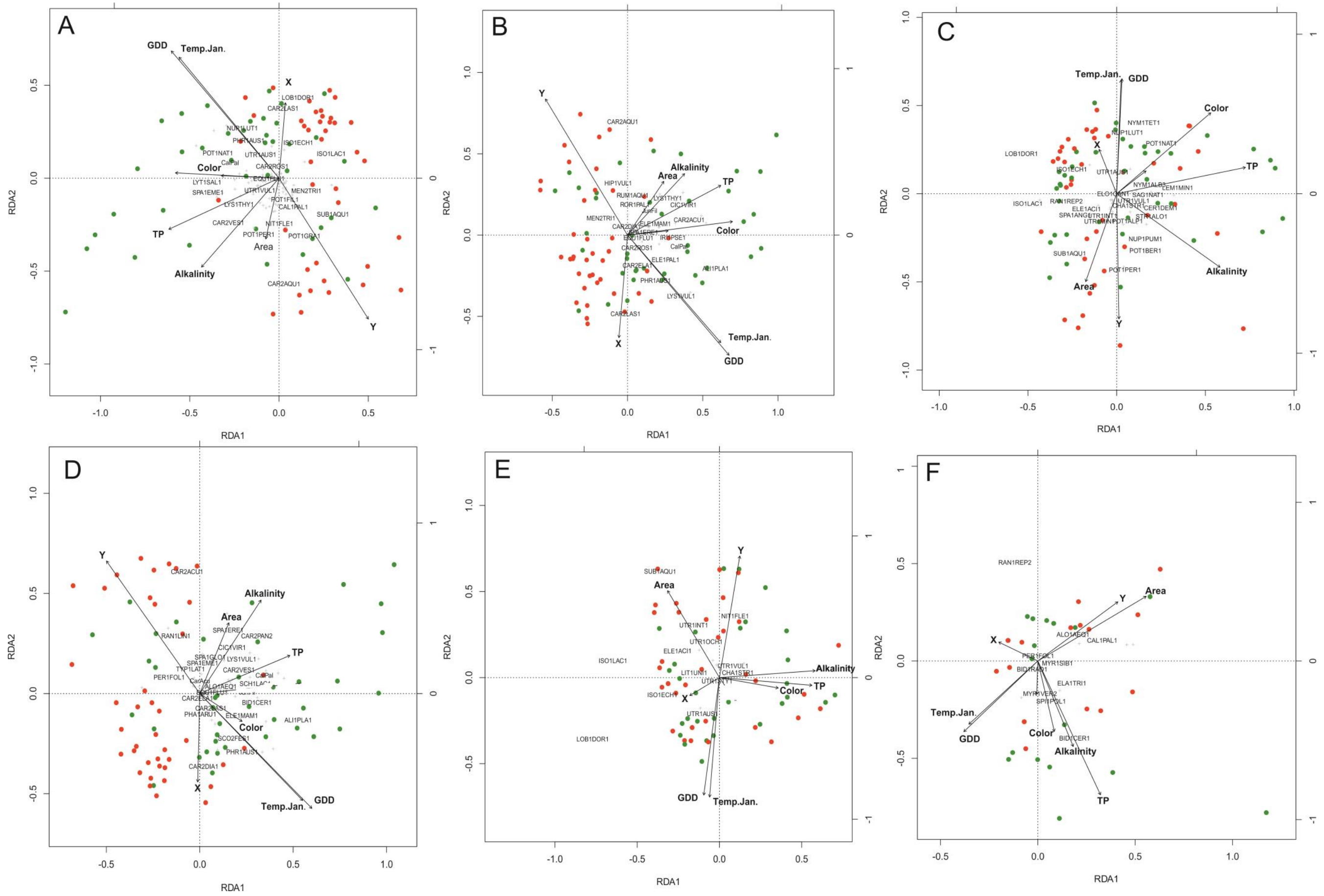
Fig. 3. RDA ordination plots of the environmental gradients for community composition of (A) all macrophytes, (B) helophytes, (C) hydrophytes, (D) competitors, (E) stress-tolerants, and (F) ruderals. Supra-aquatic lakes are shown in red and subaquatic lakes in green. Text will be used for species names with higher priority if labels overlap based on ORDITORP in Vegan. Area: Surface area, GDD: Growing degree days, Supra: Delineation between supra- and subaquatic lakes, Temp.Jan.: Temperature of January, TP: Total phosphorus. Species abbreviations are based on the first three letters of genera and species names. Species abbreviations with full names are found in the Online Resources. 
